\title{
PRESERVATION OF ENVIRONMENTAL QUALITY AND TOURIST INVESTMENTS \#
}

\author{
Juan G. Brida ${ }^{\mathrm{a} *}$, Edgar J. Sanchez Carrera ${ }^{\mathrm{b}}$, Elvio Accinelli ${ }^{\mathrm{c}}$
}

${ }^{a}$ Free University of Bolzano, School of Economics and Management, Bolzano, Italy, e-mail: JuanGabriel.Brida@unibz.it

${ }^{\mathrm{b}}$ Department of Economics, University of Siena, Italy, e-mail: sanchezcarre@unisi.it

c Universidad Autónoma de San Luis Potosi, San Luis Potosi, México, e-mail: elvio.accinelli@eco.uaslp.mx

${ }^{*}$ Corresponding author

\begin{abstract}
We develop a theoretical model to analyze the incentives for hotel chains to make environmentally friendly investments. We show that the level of investment of hotel chains to improve the environmental quality of a tourist destination depends positively on two factors: tourist demand and the level of aggregate income. The framework is based on a model of horizontal differentiation à la Hotelling. By introducing a demand function for tourist commodities, we show that an increase in total income encourages hotel chains in the regions with higher demand to invest on environmental quality.
\end{abstract}

Keywords: Environmental investment, hotel chain, Hotelling competition, sustainable tourism

\section{Introduction}

Hotels that have applied programs on environmental quality have experienced an increase of demand, which results in direct financial gains (Alvarez et al., 2001 and Burgos et al., 2002). Regarding the theoretical part, there are some models on sustainable tourism and the exploitation of natural capital that consider the effect that international hotel chains have on environmental quality (e.g. Casagrandi and Rinaldi, 2002; Dunning and McQueen, 1981, 1982; Giannoni and Maupertuis, 2005). Since the explosive growth of the hotel industry, the importance of investments on environmental quality has increased in order to maintain and increase the tourist demand of a destination. Tourists have shown to be grateful for having the natural

\footnotetext{
\# The research was supported by the Free University of Bolzano, project: "Market imperfections and tourism policy". We would also like to thank the helpful comments of anonymous referees. A preliminary version of this paper was presented at the $24^{\text {th }}$ EuroCHRIE congress, Thessaloniki (Greece), 24-26 October 2006.
} 
resources of a region, such as good bathing water, beach quality, air quality and animal protection. (see Gios et al. 2006). Some approaches have shown that there is willingness among tourists to pay more for environmentally friendly products and tourist facilities (see Bumgarner, 1994; Gustin and Weaver, 1996 and Hornemann et al., 1997). McMinn (1997) and Hunter (1997) pointed out that policy makers on tourist activities are interested in increasing tourist demand (or flux of tourists) but first it is necessary to invest on environmental quality and a sustainable use of natural resources.

An important distinction of the tourist industry is that the activities of a specific tourist firm directly affect the environmental quality of its region. Moreover, when we assume that the impact of one hotel on the environment has consequences for the perceived quality of all the hotels in the area, we can expect that the externalities across tourist establishments constitute a key factor to understanding the industry.

To deepen on the above statements and model the problem, we introduce a Hotelling's framework on the stability of competition along with the notion of spatial competition in a duopoly situation. Our duopoly situation is a competition between two hotel chains located on a tourist region. Being that the environmental quality of a destination is one of the main factors which determines the demand for tourist services, we study the incentives for a hotel chain to invest on environmental quality.

This paper is organized as follows. In the next section, we introduce the basic ingredients of Calvera's model (Calveras, 2003) and then modify it in order to show how the demand for tourist commodities and changes in total income encourage hotel chains to invest on environmental quality. Section 3 gives the mathematical results and conditions for tourist flow and accommodation. Section 4 details the incentives to invest in environmental quality under changes in total income. Conclusions and future research are summarized in the last section.

\section{The model}

We present a model of spatial competition à la Hotelling ${ }^{1}$. Let us suppose that there are two tourist destinations in the world, regions $A$ and $B$, each one located at the extreme points of a line of length 1 . Figure 1 represents the competition between these two complementary regions.

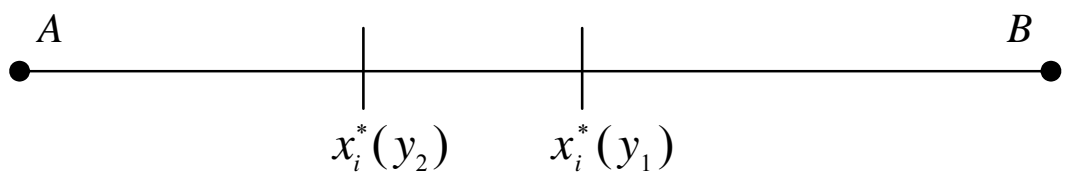

Figure 1 Linear distribution of tourist world: movements of the indifference point when $r_{A}>r_{B}$, and the total income increases from $y_{1}$ to $y_{2}$. 
Let us suppose that the tourist population is uniformly distributed along this line and that there are $n_{R}$ hotels with an exogenous capacity of $k$ units in each region, $R \in\{A, B\}$. The tourist has a unit distance cost of transportation $\tau$. Therefore, a tourist located at point $x$ in the linear world going on vacation to region $A$ has a transportation cost of $\tau . X$ while going to region $B$ has a transportation cost of $\tau(1-X)$. The environmental quality of the region is jointly determined by the quality of all the hotel establishments within the region. If we denote $Q_{R_{i}} \geq 0$, as the investment on environmental quality of hotel $R_{i}$ and $\alpha_{R}$ represents a region's idiosyncratic parameter, like the type of natural attractions that there exist in the region, then the quality of region $R$ is defined by:

$$
q_{R}=\alpha_{R} \frac{\sum^{n_{R}} Q_{R_{i}}}{n_{R}}
$$

Clearly, if a new hotel enters the region and does not invest on environmental resources, then the environmental quality decreases. Sustainable tourism is a form of tourism that uses natural resources and cultural heritage to increase the number of visitors and profits from tourist activities, but preserves them for future generations. This can also be defined from the concept of carrying capacity ${ }^{2}$ : a development of tourist activities is sustainable if it is within the carrying capacity of tourist resources (Casagrandi and Rinaldi, 2002). If the carrying capacity is exceeded, deterioration of the area's environmental resources, diminished visitor satisfaction, and/or adverse impacts upon the society, economy and culture of an area can be expected to ensue. That is why tour operators are important agents in developing a sustainable tourist industry by controlling tourist activity so it does not exceed its carrying capacity. The tour operators are those agents that participate in tourist activities as middlemen between the final consumer (tourist) and the tourist product (travel and stay in tourist destination). In our model we suppose the existence of one tour operator $T O_{R}$ in each region $R \in\{A, B\}$. The objective of tour operators $T O_{A}$ and $T O_{B}$ is to distribute the tourism regarding the hotel capacity of each region, for this action they receive a fixed portion of the profits $\pi$ of tourist accommodation. The $T O_{R}$ obtains $(1-\delta) \pi$ while the hotels get $\delta \pi$, where $\delta \in(0,1)$. Let $p_{R}$ be the price for each unit fixed by $T O_{R}$. We assume that $p_{R}$ is the same for all hotels within each region. Each $T O_{R}$ is a price-taker (takes as given the prices of its region and the prices of the other tour operator) that maximizes its profits. Each $T O_{R}$ finds an optimum that depends on the optimum of the other $T O_{R}$. Then, using an action and reaction mechanism, they reach the equilibrium of the system as a fixed point of this process. 
We use a simple partial model where all consumers share the same CobbDouglas utility function (see Accinelli et al., 2007, and Skak, 2004):

$$
u(c, d)=d^{\beta} c^{1-\beta}
$$

where $0<\beta<1, d \geq 1$ is the number of vacation days that a tourist occupies one unit of hotel and $c \geq 0$ is the consumption of other goods. It is realistic to impose a time limit of $D$ days for which each hotel room can be occupied: $1 \leq d \leq D$. Income of each consumer and income distribution are given exogenously by the linear equation

$$
y=c+r d
$$

where $r$ is the rent price of the hotel room and the price of $c$ is normalized to 1 . We maximize the utility function subject to the restriction budget (3) and having computed the first-order conditions we obtain the demand function for the occupation of the hotel rooms:

$$
d=\beta \frac{y}{r}
$$

From (4) we can formally define an individual measure of welfare for the tourist located at point $x$ with demand $d_{R}$ for hotel room in the region $R \in\{A, B\}$ of quality $q_{R}$ and price $p_{R}$. This measure can be given by:

$$
U(x, R)=d_{R}+v q_{R}-p_{R}-\tau|x-R|
$$

where $d_{R}$ is the demand for days of rest in a hotel room of the region $R, v$ captures the effect of the specific quality of the region, and $|x-R| \in\{x, 1-x\}$ is the distance between $x$ and region $R$.

Starting from (4), we can proceed to analyze the behavior of hotel chains regarding investment on environmental quality.

\section{Tourist flow and accommodation}

Let us consider an individual tourist located at $x$ who wants to go to region $A$ or $B$. By substituting (4) in (5) we obtain the corresponding levels of welfare: 


$$
U(x, A)=\beta \frac{y}{r_{A}}+v q_{A}-p_{A}-\tau x
$$

and

$$
U(x, B)=\beta \frac{y}{r_{B}}+v q_{B}-p_{B}-\tau \chi
$$

If we suppose that the individual is indifferent between going to region $\mathrm{A}$ or $\mathrm{B}$ and is located at point $x^{*}$; then the tourist individual welfare verifies:

$$
U\left(x^{*}, A\right)=U\left(x^{*}, B\right)
$$

Using the above equality we can compute the tourist flow faced by each region $A$ and $B$ denoted as $F_{A}=x^{*}$ and $F_{B}=\left(1-x^{*}\right)$ respectively, this is because all tourists located to the left of $x^{*}$ prefer to go on vacation to region $A$ and all those located to the right of $x^{*}$ prefer to go on vacation to region $B$.

By substituting (6) and (7) in (8) we obtain a linear equation on the variable $x$, whose solution $x^{*}$ is given by:

$$
x^{*}=\left(p_{A}, p_{B}\right)=\frac{\beta y\left(\frac{1}{r_{A}}-\frac{1}{r_{B}}\right)+v\left(q_{A}-q_{B}\right)-\left(p_{A}-p_{B}\right)+\tau}{2 \tau},
$$

where prices, qualities and transportation costs are given. Note that if, for example, $r_{A}$ $>r_{B}$, then $x^{*}\left(p_{A}, p_{B}\right)$ depends negatively on the income $y$, implying that an increase on income produces a movement of the indifference point towards region $A$. Then, when $r_{A}>r_{B}$, an increase on income produces an increase on the total demand for rooms in region $B$ (see figure 1). Therefore there is an increase in the demand for cheap rooms and the demand for expensive rooms decreases. Similar considerations can be deduced from effects of changes in room prices or environmental quality of the regions. The second step is that each $T O_{R}$ should solve the distribution with regard to the capacity of each region. The price of accommodation for each hotel in a given region $R$ is the same since they all exhibit the same quality $q_{R}$. Consequently, each tour operator $T O_{A}$ and $T O_{B}$ sets the price to:

$$
\max _{p_{A}}(1-\delta) p_{A} X^{*}\left(p_{A}, p_{B}\right)
$$

subject to: 


$$
n_{A} k \geq x^{*}\left(p_{A}, p_{B}\right)
$$

and

$$
\max _{p_{B}}(1-\delta) p_{B}\left(1-x^{*}\left(p_{A}, p_{B}\right)\right)
$$

subject to:

$$
n_{B} k \geq\left(1-x^{*}\left(p_{A}, p_{B}\right)\right)
$$

respectively. It is assumed that $k$ is sufficiently large for the restrictions to hold. From the previous solutions we obtain the Nash-Cournot equilibrium prices fixed by the $\mathrm{TO}_{R}$ :

$$
\begin{aligned}
p_{A}^{*}\left(q_{A}, q_{B}\right) & =\tau+\frac{\beta y\left(\frac{1}{r_{A}}-\frac{1}{r_{B}}\right)+v\left(q_{A}-q_{B}\right)}{3} \\
p_{B}^{*}\left(q_{A}, q_{B}\right) & =\tau-\frac{\beta y\left(\frac{1}{r_{A}}-\frac{1}{r_{B}}\right)+v\left(q_{A}-q_{B}\right)}{3}
\end{aligned}
$$

Note that an increase on the total income produces an increase on price of $T O_{R}$ services in the cheapest region, and a decrease on price of $T O_{R}$ services in the most expensive region. For these values of equilibrium prices we have that:

$$
x^{*}\left(p_{A}^{*}\left(q_{A}, q_{B}\right), p_{B}^{*}\left(q_{A}, q_{B}\right)\right)=x^{*}\left(q_{A}, q_{B}\right)=\frac{\beta y\left(\frac{1}{r_{A}}-\frac{1}{r_{B}}\right)+v\left(q_{A}-q_{B}\right)+3 \tau}{6 \tau}
$$

which gives the value of the indifference point as a function of $q_{A}$ and $q_{B}$.

\section{Investment on environmental quality}

Let us continue with the tourist regions $A$ and $B$ (for example, our country $A$ and the rest of the world $B$ ). A hotel chain is formed by $\hat{n}=\hat{n}_{A}+\hat{n}_{B}$ hotels, with $\hat{n}_{A}$ in region $A$ and $\hat{n}_{B}$ in region $B$. Let's suppose that $A$ is the home region of a local 
chain. Then, a completely local chain will be formed only by hotel establishments in region $A$, whereas an international chain will also have hotel establishments in the rest of the world, i.e., the region $B$. Each investment on environmental quality has a cost $c\left(Q_{R_{i}}\right)$, where $c^{\prime}\left(Q_{R_{i}}\right)>0, c^{\prime \prime}\left(Q_{R_{i}}\right)>0$ and $c^{\prime}(0)=0$.

Suppose that hotel $i$, established in home region $A$, maximizes its profits; i.e.

$$
\max _{Q_{A_{i}}} \pi_{i}\left(Q_{A_{i}}\right)=\max _{Q_{A_{i}}} \delta p_{A}^{*} \frac{x^{*}\left(q_{A}, q_{B}\right)}{n_{A}}-c\left(Q_{A_{i}}\right)
$$

The first-order conditions for problem (15) are:

$$
\delta\left[\frac{v}{3} \frac{\alpha_{A}}{n_{A}} \frac{x^{*}\left(q_{A}, q_{B}\right)}{n_{A}}+\frac{p_{A}^{*}}{n_{A}} \frac{v}{6 \tau} \frac{\alpha_{A}}{n_{A}}\right]-c^{\prime}\left(Q_{A_{i}}\right)=0 \quad\left(\text { for } i=1 \ldots n_{A}\right)
$$

or equivalently:

$$
2 \delta \frac{v \alpha_{A}}{3 n_{A}^{2}} x^{*}\left(q_{A}, q_{B}\right)=c^{\prime}\left(Q_{A_{i}}\right)=0 \quad\left(\text { for } i=1 \ldots n_{A}\right) .
$$

Then, the hotel chain that maximizes its profits solves the problem:

$$
\max _{Q_{A_{i}}} \pi_{\hat{n}_{A}, \hat{n}_{B}}\left(\hat{Q}_{\hat{n}_{A}}\right)
$$

where:

$$
\hat{Q}_{\hat{n}_{A}}=\sum_{i=1}^{\hat{n}_{A}} Q_{A_{i}}
$$

is the vector of quality investments for each of the hotel establishments belonging to the chain, and where:

$$
\pi_{\hat{n}_{A}, \hat{n}_{B}}\left(\hat{Q}_{\hat{n}_{A}}\right)=\delta\left[\hat{n}_{A} p_{A}^{*} \frac{x^{*}\left(q_{A}, q_{B}\right)}{n_{A}}+\hat{n}_{B} p_{B}^{*} \frac{1-x^{*}\left(q_{A}, q_{B}\right)}{n_{B}}\right]-\sum_{i=1}^{\hat{n}_{A}} c\left(Q_{A_{i}}\right)
$$


with $\sum_{i=1}^{\hat{n}_{A}} C\left(Q_{A_{i}}\right)$ being the separable costs of investing in all the hotel establishments of the chain. From this we can obtain the first-order conditions (for $\left.i=1 \ldots \hat{n}_{A}\right)$ :

$$
\frac{\delta \hat{n}_{A}}{n_{A}}\left[\frac{\partial p_{A}^{*}}{\partial Q_{A_{i}}} x^{*}+\frac{\partial x^{*}}{\partial Q_{A_{i}}} p_{A}^{*}\right]+\frac{\delta \hat{n}_{B}}{n_{B}}\left[\frac{\partial p_{B}^{*}}{\partial Q_{A_{i}}}\left(1-x^{*}\right)-\frac{\partial x^{*}}{\partial Q_{A_{i}}} p_{B}^{*}\right]=c^{\prime}\left(Q_{A_{i}}\right)
$$

that can be written as

$$
\frac{\delta v \alpha_{A}}{3 n_{A}}\left[\left(\frac{\hat{n}_{A}}{n_{A}}+\frac{\hat{n}_{B}}{n_{B}}\right) x^{*}+\frac{1}{2 \tau}\left(\frac{\hat{n}_{A}}{n_{A}}+\frac{\hat{n}_{B}}{n_{B}}\right) p_{A}^{*}-2 \frac{\hat{n}_{B}}{n_{B}}\right]=C^{\prime}\left(Q_{A_{i}}\right)
$$

The system of equations (21) indicates the decision about how much to invest in an establishment $i$ situated in the home region $A$. Note also that the second term of (21) is multiplied by $n_{B} / n_{B}$, the participation in capacity of the chain in the total of chains in the region $B$. Then, if $\hat{n}_{B}$ increases, the incentive to invest on environmental quality of hotels located in region $A$ decreases.

Given the total income $y$, let $x^{*}(y)$ be the solution of $(8)$ and $\left(p_{A}^{*}(y), p_{B}^{*}(y)\right)$ be the Nash-Cournot solution obtained in (14). If we assume that $y_{1}<y_{2}$ and $r_{A}>r_{B}$, then we have that $x^{*}\left(y_{1}\right)>x^{*}\left(y_{2}\right), p_{A}^{*}\left(y_{1}\right)>p_{A}^{*}\left(y_{2}\right)$ and $p_{B}^{*}\left(y_{1}\right)<p_{B}^{*}\left(y_{2}\right)$. This means that $x^{*}$ and $p_{A}^{*}$ are decreasing functions of the total income $y$. Then, from the system of equations (22) it follows that an increase in total income $y$ produces a decrease in investment on environmental quality in the region where the prices of rooms are higher. The following proposition resumes our main conclusions.

Proposition: If total income $y$ increases, then the incentive to invest on environmental quality increases in the region where the price of the room $r_{R}$ is lower and diminishes in the other region. In other words, when $y$ increases, there is an increase in the quantity of tourists in the region with cheaper rooms, implying an incentive to invest on environmental quality in such region. In the other region the situation is the opposite: there are less tourists and less incentives to invest on environmental quality.

\section{Concluding remarks}

Chains are a specific form of hotel concentration, involving the unified management of a certain number of establishments, according to diverse models, but 
having in common the same management, the same productive process and identical objectives. To some extent, they have ambitious initiatives, depending on the chain, for the protection of the environment and the development of sustainable tourism, such as, the implementation of different measures in order to avoid and/or correct impacts, the implementation of environmental management systems in their hotels, etc.

Nevertheless, we showed the significance for a hotel chain to invest on environmental quality when there is an increase in the income per capita of visitors, which translates into a higher tourist demand.

For a hotel chain, the promotion of sustainable tourism development is essential for maximizing its economic benefits and minimizing its environmental impact.

The main result shows up when incomes of tourists increase, which implies that the hotel chain must increase the investment on the environmental quality of the region where there is an increase of tourist activity.

If we consider the controversy between the two $T O_{R}$ as a Counot game, then the equilibrium point of the reaction curves moves outward in the $\boldsymbol{p}_{A} \boldsymbol{p}_{\boldsymbol{B}}$ plane when the total income increases (see figure 2).

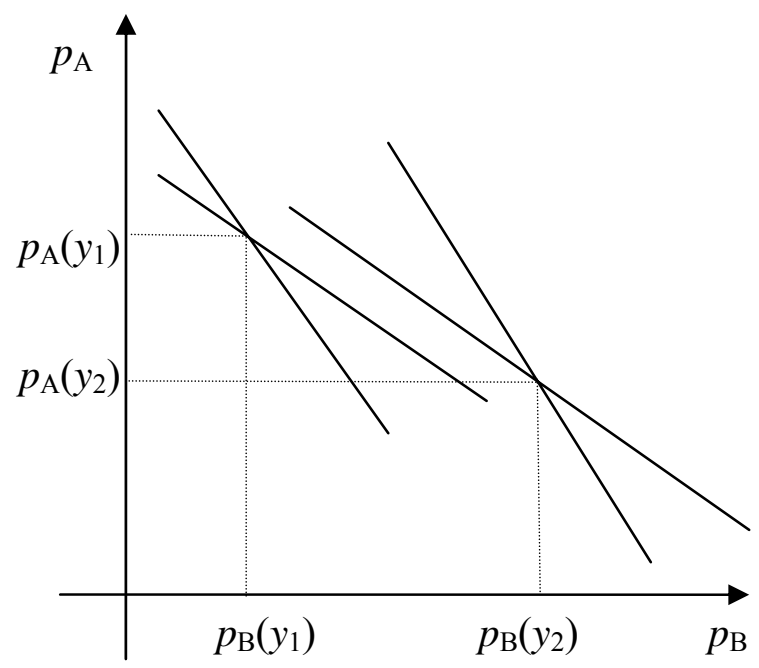

Figure 2 Movements of the reaction curves: when $r_{A}>r_{B}$, and the total income increases from $y_{1}$ to $y_{2}$ then the equilibrium point moves down and to the right.

There are some research lines to be explored:

1. On the inter-temporal trade-off between the investment on environmental quality and the tourist flow to ensure sustainable tourism. In this perspective, this will be a later step in our research. In particular, we can improve our model by introducing different types of hotel rooms in the two or more regions. In this case, the utility 
function of the tourists for rooms will depend on two different (non homogeneous) goods.

2. We should consider that the hotel industry is characterized by an increasing presence of hotel chains and, in particular, of international chains. Local and international hotel chains can have very different incentives to invest on environmental quality. For example, chain affiliation enables a hotel's access to information on environmental protection measures as well as sharing resources and taking advantage of economies of scale.

3. Also, it is important to consider that an international chain can move from a region to another if the environment quality decreases. These elements are essential to introduce regulations in the tourism sector and to implement government policies to protect the environmental quality.

4. As a final comment, the above model on tourism economics is only a theoretical framework on the relationships between the income of visitors, environmental investment, and tourist demand. But it can be empirically tested. For instance, an important future research is to test the causality of income and tourist demand for hotel chains. By using a Granger causality test, we are able to check the bidirectionality or unidirectionality (on causality) among tourist demand, environmental quality investment and income per capita of visitors. Moreover, a Cointegration analysis can be studied to hold the long run relationship of the variables presented in our theoretical model. However, it is always important to note that a theoretical model is already tested with its "level on real assumptions", and the importance for hotel chains to invest on environmental policies is not discussed since it is a common knowledge.

\section{Endnotes}

1 It is a simple microeconomic model of horizontal differentiation under spatial competition (due to Hotelling, 1929). For details see (Mas-Colell et al., 1995; Shy, 1996).

${ }^{1}$ The World Tourism Organization defines the tourism carrying capacity of a region as the maximum number of people that may visit the tourist destination without causing destruction of the physical, economic and socio-cultural environment and an unacceptable decrease in the quality of visitors' satisfaction (WTTC 1991). 


\section{References}

1. Accinelli, E., J. G.Brida, J. S. E. Carrera (2007) Second Homes: The Effects on Social Welfare of a Change on the Valuation of Individual Opportunity Cost. Anatolia: an international journal of tourism and hospitality research 18(1), pp. 85-96

2. Alvarez, M. J., J. J. Burgos, J. J. Cespedes (2001) An analysis of environmental management, organizational context and performance of Spanish hotels. OMEGA The International Journal of Management Science 29(1), pp. 457-471

3. Bumgarner, A. (1994) The Mainstreaming of Ecotourism. ASTA Agency Management pp. 54-58

4. Burgos, J., G. Cano, L. Céspedes (2002) Planning and control of environmental performance in hotels. Journal of Sustainable Tourism 10(3), pp. 207220

5. Calveras, A. (2003) Incentives of international and local hotel chains to invest in environmental quality. Tourism Economics 9(3), pp. 297-306

6. Casagrandi R., S. Rinaldi (2002) A theoretical approach to tourism sustainability. Conservation Ecology 6(1), p. 13

7. Dunning, J. H., M. McQueen (1981) The eclectic theory of international production: a case study of the international hotel industry. Managerial and Decision Economics 2(4), pp. 220-228

8. Dunning, J. H., M. McQueen (1982) The electric theory of the multinational enterprise and the international hotel industry. In Rugman, A. M. (Eds) (1982) New Theories of Multinational Enterprise. St Martin's, New York

9. Giannoni S., M.-A. Maupertuis (2005) Environmental quality and long run tourism development a cyclical perspective for small island tourist economies, NRM - Natural Resources Management, Fondazione Eni Enrico Mattei. Università di Corsica, Italy.

10. Gios, M., I. Goio, S. Notaro, R. Rafaelli (2006) The Value of Natural Resources for Tourism: a Case Study of the Italian Alps. International Journal of Tourism Research 8(2), pp. 77-85

11. Gustin, M., P. Weaver (1996) Are hotels prepared for the environmental consumer? Hospitality Research Journal 20(2), pp. 1-14

12. Hornemann, L., Beeton, R., Huie, J. (1997) Environmental quality assurance: Are consumers of hospitality and tourism services willing to pay? Proceedings of The Hospitality Industry in an Age of Environmental Concern, The International Association of Hotel Management Schools, Brisbane. University of Queensland, Centre for Hospitality and Tourism, pp. 112-125

13. Hotelling, H. (1929) Stability in Competition. Economic Journal 39, pp. $41-57$

14. Hunter, C. (1997) Sustainable tourism as an adaptive paradigm. Annals of Tourism Research 24(4), pp. 850-67 
15. Mas-Colell, A., Whinston, M., Green J. (1995) Microeconomic Theory. Oxford University Press.

16. McMinn, S. (1997) The challenge of sustainable tourism. The Environmentalist, 17(2), pp. 135-141

17. Shy, O. (1996) Industrial Organization, The MIT Press.

18. Skak, M. (2004) Restricting Ownership of Vacation Homes. Tourism Economics 10 (4), pp. 435-447.

19. World Travel and Tourism Council (WTTC) (1991) WTTC Policy: Environmental Principles. Brussels: World Travel and Tourism Council.

SUBMITTED: 11.05 .2007

ACCEPTED: 26.12.2007 